\title{
Numerical Investigation on Primary Atomization Mechanism of Hollow Cone Swirling Sprays
}

\author{
Jia-Wei Ding, Guo-Xiu Li, Yu-Song Yu, and Hong-Meng Li \\ School of Mechanical, Electronic and Control Engineering, Beijing Jiaotong University, Beijing 100044, China \\ Correspondence should be addressed to Guo-Xiu Li; li_guoxiu@yahoo.com
}

Received 23 December 2015; Revised 27 March 2016; Accepted 10 April 2016

Academic Editor: Sourabh V. Apte

Copyright (C) 2016 Jia-Wei Ding et al. This is an open access article distributed under the Creative Commons Attribution License, which permits unrestricted use, distribution, and reproduction in any medium, provided the original work is properly cited.

\begin{abstract}
The atomization process of swirling sprays in gas turbine engines has been investigated using a LES-VOF model. With fine grid resolution, the ligament and droplet formation processes are captured in detail. The spray structure of fully developed sprays and the flow field are observed firstly. A central recirculation zone is generated inside the hollow cone section due to the entrainment of air by the liquid sheet and strong turbulent structures promote the breakup of ligaments. At the exit of injector nozzle, surface instability occurs due to disturbance factors. Axial and transverse mode instabilities produce a net-like structure ligament zone. Finally, the generation mechanism of the droplet is analyzed. It is found that the breakup mechanism of ligaments is located at the Raleigh capillary region. Axial symmetry oscillation occurs due to the surface tension force and the capillary waves pinch off from the neck of the ligaments. Secondary breakup and coalescence occur at the "droplet zone," resulting in a wider distribution curve at the downstream area.
\end{abstract}

\section{Introduction}

Liquid atomization is an important process in internal combustion engines. The quality of spray atomization directly affects fuel combustion, which consequently determines engine performance. In gas turbine engines, pressure swirl injectors are widely used because of their good atomization capability and geometrical simplicity [1]. In a pressure swirl injector, liquid is injected through twisty slots; thus tangential velocity is endued to the fluid in orifice and spray cone emerges due to the centrifugal force. The liquid sheet becomes unstable and breaks up into ligaments, and then ligaments break up into droplets and secondary breakup occurs downstream of the spray. The atomization of swirling jet is a complex process that is affected by many factors and its mechanism needs to be understood properly [2].

Over the past several decades, a series of theoretical and experimental investigations have been performed in both industry and academia for a better understanding of the atomization process of swirling jet [3-5]. Ponstein [6] investigated the growth of disturbance of an annular swirling liquid sheet based on instability analysis. In his research, the viscosity of both phases has been neglected. Liao et al. [7] developed a theoretical model to predict the performance of simplex atomizer based on the study of an inviscid, swirling annular liquid sheet. Ibrahim and Jog [8] studied the nonlinear instability and breakup of an annular liquid sheet using a perturbation expansion method, the effect of liquid Weber number, initial disturbance, and gas swirl strength on the breakup characteristics is investigated. So far, the literature on theoretical investigation was based on many simple assumptions and it is difficult to predict the sheet breakup accurately without taking into account the complex interaction between liquid and gas.

Experimentally, studies are carried out to predict the atomization characteristics (spray angle, liquid film breakup length, and drop size distribution) of swirling spray [9-13]. Although there have been many investigations on the spray characteristics of swirling jet, most of them focus on the macroscopic properties of atomization, and investigations on liquid film instability and ligament breakup process are still lacking. Also, to observe the small and dense region where ligaments and droplets occur, high spatiotemporal resolution of visualization technology is needed. So far, the entire 
breakup mechanism of swirling jet has not been revealed yet by experiment and further investigations are demanded.

In recent years, with the development of interface capturing methods, numerical simulations have been carried out to predict the breakup process of liquid jet. Ménard et al. [15] used coupled level set/VOF/ghost methods to investigate the atomization of a liquid jet injected into still gas. Desjardins et al. [16] applied combined level set/VOF method to the primary breakup of a straight liquid jet. De Villiers et al. [17] used LES-VOF method to investigate the atomization of a round jet influenced by nozzle flow. Herrmann et al. [18-20] discussed the influence of gas/liquid density ratio on liquid jet penetration and the primary breakup characteristics using level set method and fine grid. Shinjo and Umemura [21, 22] performed a detailed numerical simulation of straight liquid jets of diesel fuel. As a result, they were able to characterize ligament generation and surface instability development on the liquid jet core influenced by aerodynamics. Siamas et al. [23] investigated the surface instability and flow field of a swirling annular jet using VOF method, but the simulation only focuses on the region close to the nozzle exit. Using high performance computer system and with fine grid resolution, the ligament and droplet formation process can be captured correctly which is hard to be observed in experiment investigation, allowing a detailed study of liquid atomization mechanism.

In the present study, a volume of fluid (VOF) interface tracking method and a large eddy simulation (LES) model were used for computing the atomization process of swirling sprays. The present research mainly focuses on the breakup process of liquid film and the droplet formation process. The ligament structure and droplet formation mechanism will be identified. The remainder of this paper is organized as follows: Section 2 presents the numerical methodology and the simulation setup procedures. Section 3 presents the numerical results and discussion. Finally, Section 4 presents the concluding remarks.

\section{Numerical Method}

2.1. Governing Equations. In large eddy simulation, the subgrid structures are modelled while the large eddy turbulent structures are resolved on a computational grid.

In the present model, the simultaneous flow is treated as immiscible, incompressible continuum fluids with an effective viscosity and surface tension. The continuity and momentum equations are as follows:

$$
\begin{gathered}
\frac{\partial \overline{u_{i}}}{\partial x}=0 \\
\frac{\partial \rho \overline{u_{i}}}{\partial t}+\frac{\partial \rho\left(\overline{u_{i}} \overline{u_{j}}\right)}{\partial x_{i}}=-\frac{\partial \bar{p}}{\partial x_{i}}+\frac{\partial}{\partial x_{i}}\left(\mu \frac{\partial \overline{u_{i}}}{\partial x_{j}}\right)-\frac{\partial \tau_{i j}}{\partial x_{j}}+\overline{F_{s}} \\
+\bar{G}
\end{gathered}
$$

where $u_{i}$ and $u_{j}$ are velocities and the subscript $i, j$ indicated the coordinate $(x, y)$ indices, $\rho$ is density, $p$ is pressure, $\mu$ is kinetic viscosity, $\tau_{i j}$ is subgrid scale (SGS) stress, $F_{s}$ is surface tension, and $G$ is the force of gravity.

The surface tension force $F_{s}$ is represented as a continuous surface force model [24]:

$$
F=\int_{s(t)} \sigma k^{\prime} \vec{n} \delta\left(\vec{x}-\vec{x}^{\prime}\right) d S \approx \sigma k \delta_{s} \vec{n},
$$

where the interface unit normal vector $\vec{n}$ and the curvature of the interface $\kappa$ are given by

$$
\kappa=\nabla \cdot\left(\frac{\vec{n}}{|\vec{n}|}\right) .
$$

SGS stress can be approximated by the SGS model. In the present simulation, the Smagorinsky model [25] is used and it can be written as

$$
\bar{\tau}_{i j}=2 v_{t} \bar{S}_{i j}-\frac{1}{3} \delta_{i j} \bar{\tau}_{k k}
$$

where $v_{t}=C_{s} \Delta^{2}\left(2 \bar{S}_{i j} \bar{S}_{i j}\right)^{1 / 2}$ is SGS viscosity, $\bar{S}_{i j}=$ $(1 / 2)\left(\partial \bar{u}_{i} / \partial x_{j}+\partial \bar{u}_{j} / \partial x_{i}\right)$ is the constant, and $C_{s}$ is the Smagorinsky model coefficient of 0.18 .

The liquid volume fraction $\gamma$ represents the indicator function with $\gamma=0$ for gas and $\gamma=1$ for liquid. The local density and viscosity in a computational cell are given in terms of the liquid volume fraction by

$$
\begin{aligned}
& \rho=\gamma \rho_{l}+(1-\gamma) \rho_{g}, \\
& \mu=\gamma \mu_{l}+(1-\gamma) \mu_{g},
\end{aligned}
$$

where subscripts $l$ and $g$ represent the liquid and gas phases, respectively.

The indicator function obeys a transport equation as follows:

$$
\frac{\partial \gamma}{\partial t}+\nabla \cdot(\bar{u} \gamma)=0
$$

2.2. VOF Scheme. The interface of liquid phase and gas phase can be computed with interface tracking or interface capturing methods. For the interface tracking methods, such as SLIC [26], PLIC [27], and their variations [28], the interfaces are reconstructed using geometric formulations. While for the interface capturing methods (CICSAM [29] and HRIC [30]), algebraic methods are employed to identify the interface locations. In HRIC method, the compressive scheme that is used to avoid the smearing of the interface could lead to interface stepping problem. To remedy this, a switching strategy that switches between compressive and noncompressive scheme called CICSAM was proposed by Ubbink [29]. In the present paper, CICSAM is used to capture the interface of liquid phase and gas phase.

CICSAM is implemented in the framework of OpenFOAM [31] as an explicit scheme which uses normalised variable diagram (NVD) and switches among different differencing schemes to furnish a bounded scalar field. Such approach could create an interface which is as sharp as 
that produced by geometric reconstruction schemes such as piecewise linear interface.

The finite volume discretization of the volume fraction convection equation based on the integral form is as follows:

$$
\begin{aligned}
& \left(\gamma_{P}^{t+\delta t}-\gamma_{P}^{t}\right) \cdot V_{P} \\
& \quad=-\sum_{f=1}^{n} \frac{1}{2}\left[\left(\gamma_{f} \cdot Q_{f}\right)^{t}+\left(\gamma_{f} \cdot Q_{f}\right)^{t+\delta t}\right] \delta t,
\end{aligned}
$$

where $P$ indicates the center of control volume, $f$ is the cell face centroid, and $Q_{f}$ is the the volumetric flux through the cell face.

For a sufficiently small time step, the diversion of $Q_{f}$ on the cell face is negligible, and (7) is reduced to

$$
\gamma_{P}^{t+\delta t}=\gamma_{P}^{t}-\frac{\delta t}{V_{P}} \sum_{f=1}^{n} \frac{1}{2} \gamma_{f}^{*} \cdot Q_{f}
$$

where $\gamma_{f}^{*}$ is the new volume fraction distribution described as

$$
\gamma_{f}^{*}=\left(1-\beta_{f}\right) \frac{\gamma_{D}^{t}+\gamma_{D}^{t+\delta t}}{2}+\beta_{f} \frac{\gamma_{A}^{t}+\gamma_{A}^{t+\delta t}}{2} .
$$

The weighting factor $\beta_{f}$ is given by NVD and can be expressed as

$$
\beta_{f}=\frac{\tilde{\gamma}_{f}-\tilde{\gamma}_{D}}{1-\tilde{\gamma}_{D}}
$$

Using the boundedness constraint in the upwind control cell $U$, the normalised variable $\widetilde{\gamma}_{f}$ and $\widetilde{\gamma}_{D}$ are given by

$$
\begin{aligned}
& \tilde{\gamma}_{f}=\frac{\gamma_{f}-\gamma_{U}}{\gamma_{A}-\gamma_{U}}, \\
& \tilde{\gamma}_{D}=\frac{\gamma_{D}-\gamma_{U}}{\gamma_{A}-\gamma_{U}},
\end{aligned}
$$

where $D, A$, and $U$ are the donor, acceptor, and upwind cells.

The cell face values of $\gamma$ are resolved by convection boundedness criteria (CBC). The HYPER-C based normalised variable is given by

$$
\tilde{\gamma}_{f \mathrm{CBC}}= \begin{cases}\min \left\{\frac{\tilde{\gamma}_{D}}{c}, 1\right\}, & 0 \leq \tilde{\gamma}_{D} \leq 1 \\ \tilde{\gamma}_{D}, & \tilde{\gamma}_{D}<0, \tilde{\gamma}_{D}>1 .\end{cases}
$$

The ULTIMATE-QUICKEST-based normalised variable is given by

$$
\begin{aligned}
& \tilde{\gamma}_{f \mathrm{UQ}} \\
& = \begin{cases}\min \left\{\frac{8 c \tilde{\gamma}_{D}+(1+c)\left(6 \tilde{\gamma}_{D}+3\right)}{8}, \tilde{\gamma}_{f \mathrm{CBC}}\right\}, & 0 \leq \tilde{\gamma}_{D} \leq 1 \\
\tilde{\gamma}_{D}, & \tilde{\gamma}_{D}<0, \tilde{\gamma}_{D}>1,\end{cases}
\end{aligned}
$$

where $c$ is the local value of Courant number at the face.
Ubbink [29] introduced the following weighting factor to switch smoothly between the less compressive differencing scheme and the upper bound of CBC:

$$
\tilde{\gamma}_{f}=\nu_{f} \tilde{\gamma}_{f \mathrm{CBC}}+\left(1-v_{f}\right) \tilde{\gamma}_{f \mathrm{UQ}} .
$$

The weighting factor $v_{f}$ is based on the cosine of the angle $\theta_{f}$ between the vector normal to the interface and the vector $\bar{d}_{f}$, which connects the centers of the donor and acceptor cells:

$$
\begin{aligned}
& N_{f}=\min \left\{\kappa_{r} \frac{\cos \left(2 \theta_{f}\right)+1}{2}, 1\right\}, \\
& \theta_{f}=\cos ^{-1}\left|\frac{(\nabla \gamma)_{D} \cdot \bar{d}_{f}}{\left|(\nabla \gamma)_{D}\right| \cdot\left|\bar{d}_{f}\right|}\right|,
\end{aligned}
$$

where $\kappa_{r} \geq 0$ is a constant introduced to control the dominance of different schemes. The recommended value is $\kappa_{r}=1$.

2.3. Numerical Methodology. The employed transient multiphase solver of OpenFOAM [31] utilizes a cell center-based finite volume method and provides a comprehensive range of discretization schemes that can be selected for each term in the equations being solved. Crank-Nicholson method with second-order accuracy is used for the time discretion of governing equations. For general field interpolations, a linear form of central differencing scheme is applied. Convective fluxes are discretized with the Gauss linear scheme. Pressure velocity coupling is addressed with the pressure implicit split operator (PISO) algorithm.

\subsection{Code Validation}

2.4.1. A 2D Droplet Test. To validate the code accuracy in capturing the liquid-gas interface, a test case of a 2D drop is simulated similar to Zheng et al. [14]. In the test case, a drop of radius $a=1$ is located in a square domain of $64 \times 64$, which is sheared by a gas flow. At the top and bottom of the domain, the tangential velocity is prescribed as $U_{0}$ and $-U_{0}$. The right and left sides of the domain are set as velocity inlet and outlet boundary. The velocity of the boundary is given by

$$
U=\frac{2 U_{0} y}{L} .
$$

Figure 1 shows the shape of the droplet at $t=16$, and the circular droplet becomes elliptical due to the shear flow. Figure 2 contains the evolution of the half-length of the 2D drop. The result shows good agreement with the value calculated by Zheng et al. [14].

2.4.2. Experiment of Swirling Spray. To validate the accuracy of the LES-VOF model in simulating the atomization process of swirling spray, a set of experiment results are carried out to compare with the simulation results. As shown in Figure 3, the experiment system contains a water supply system and 


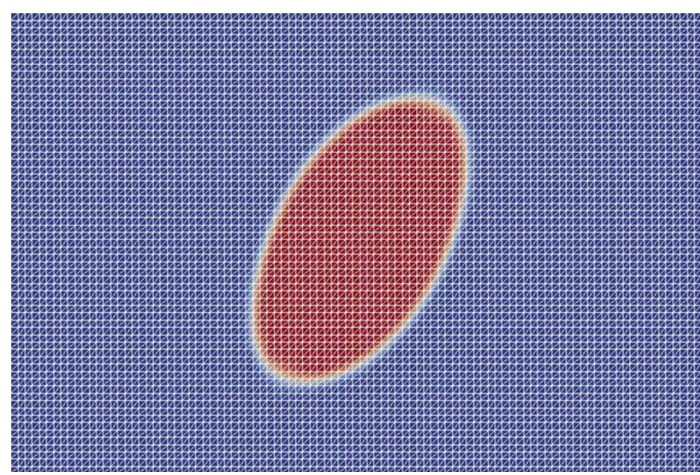

FIgURE 1: The shape of the drop at $t=16$.

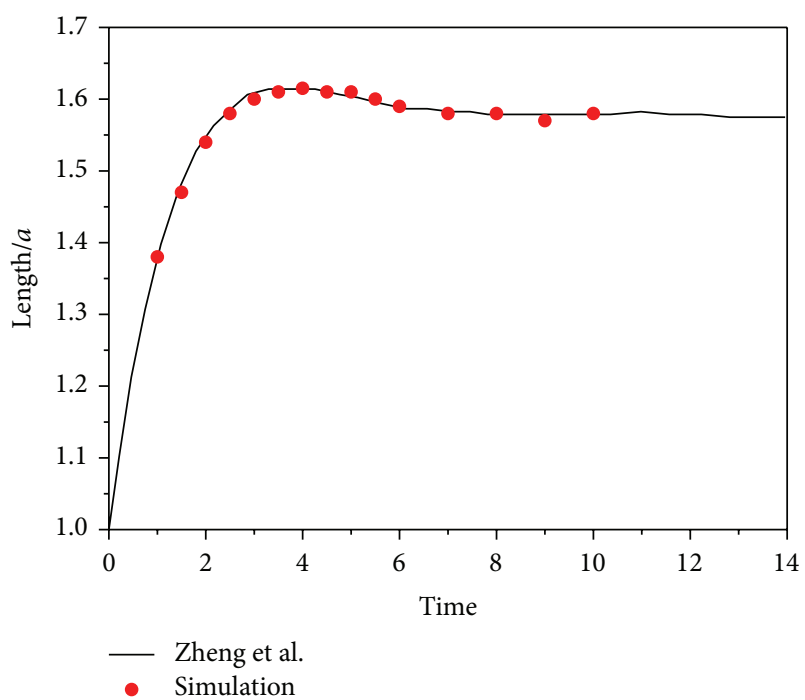

Figure 2: The droplet half-length for simulation and Zheng et al. [14].

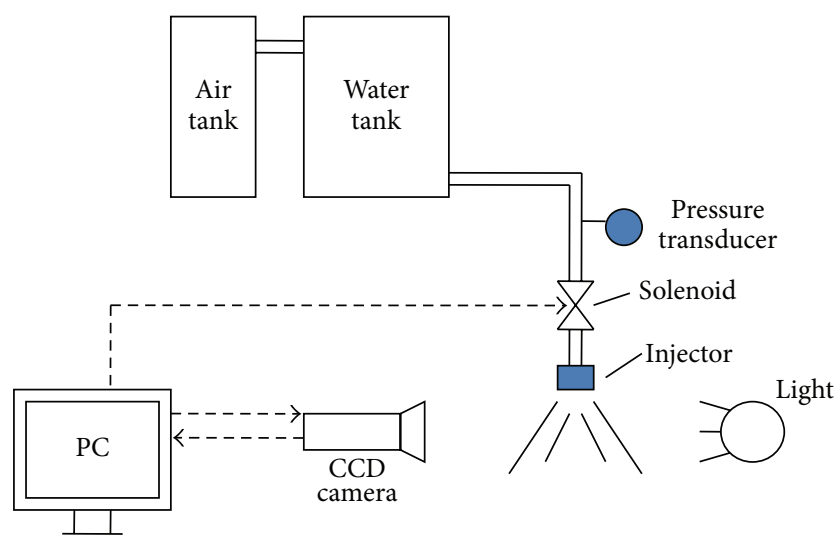

FIgURE 3: Schematic of the experimental system.

an optical system. The water supply system is composed of water tank, air tank, pressure transducers, and solenoid. The optical system is composed of CCD camera and LED panel light. The atomization process and spray angle are measured using instantaneous spray images taken by the CCD camera.
In the experiment, water is used as the stimulant of liquid fuel and injection pressures are set as $0.4 \mathrm{MPa}$ and $0.8 \mathrm{MPa}$. Figure 4 compares the snapshots of experiments and simulations for the spray. Similar spray patterns are observed for direct image comparison. In particular, general characteristics of liquid jet such as the spray angle and breakup length show up good agreement between simulation and experiment.

\section{Results and Discussion}

3.1. Simulation Setup. In the present investigation, the internal flow of the injector and the atomization process were simulated entirety. The geometry of the pressure swirl hollow cone injector is shown in Figure 1. The injector has two twisty slots and during the injection process, liquid fuel flows through the twisty slot; thus tangential velocity is endued to the fluid in orifice and spray cone emerges due to the centrifugal force.

For the objective stated in the present paper, the cold flow conditions are set similar to aviation kerosene injection. Three cases are calculated, the injection pressures $(\Delta P)$ are $0.4 \mathrm{MPa}, 0.6 \mathrm{MPa}$, and $0.8 \mathrm{MPa}$, respectively, and the ambient pressures are $0.9 \mathrm{MPa}$. The detailed flow conditions are listed in Table 1.

Figure 5 also shows the three-dimensional calculation domain and boundary condition of the present simulation. As shown in Figure 1, the axial extent of external domain is $12 \mathrm{~mm}$ and the divergence angle of the conical frustum is $70^{\circ}$, large enough to contain the whole cone spray. The resolution of the finest mesh is $7.5 \mu \mathrm{m}$, small enough to capture small droplets of $10 \sim 20 \mu \mathrm{m}$. For the computational grid, the total number of cells is 15 million, and the boundary conditions include a nonreflective outlet, uniform pressure on the cylindrical boundary, and no-slip walls. For each case, the computational time is approximately $360 \mathrm{~h}$ on a 72 processor computer cluster.

3.2. Spray Structure and Flow Field. For a pressure swirl injector, as the liquid injection pressure increases from zero, the spray structure passes through five stages such as "dribble," "distorted pencil," "onion," and "tulip" stages and fully developed spray [1]. As shown in Figure 6, the sprays are fully developed at the working injection pressure of $0.4 \sim$ $0.8 \mathrm{MPa}$.

For a fully developed swirling spray, the pressure differential and the swirl inside the orifice created a liquid film at the exit of the injector. The disturbance at the nozzle and the relative velocity between the liquid and the ambient gas induce $\mathrm{K}-\mathrm{H}$ instability to the liquid film. The surface wave grows as the liquid film moves away from the injector nozzle and eventually breaks up into several ligaments. These ligaments are deformed due to the aerodynamic and surface tension, generating droplets. Downstream of the spray, secondary breakup and coalescence occur and daughter droplets are generated.

As shown schematically in Figure 7, a hollow cone swirling spray can be divided into three zones. Zone A is the 
TABLE 1: Flow conditions.

\begin{tabular}{lcccccc}
\hline $\begin{array}{l}\text { Injection pressure } \\
p(\mathrm{MPa})\end{array}$ & $\begin{array}{c}\text { Ambient pressure } \\
p(\mathrm{MPa})\end{array}$ & $\begin{array}{c}\text { Gas density } \\
\rho_{g}\left(\mathrm{~kg} / \mathrm{m}^{3}\right)\end{array}$ & $\begin{array}{c}\text { Liquid density } \\
\rho_{l}\left(\mathrm{~kg} / \mathrm{m}^{3}\right)\end{array}$ & $\begin{array}{c}\text { Liquid viscosity } \\
\mu_{l}(\mathrm{~Pa} \mathrm{~s})\end{array}$ & $\begin{array}{c}\text { Gas viscosity } \\
\mu_{g}(\mathrm{~Pa} \mathrm{~s})\end{array}$ & $\begin{array}{c}\text { Surface tension coefficient } \\
\sigma(\mathrm{N} / \mathrm{m})\end{array}$ \\
\hline $0.4,0.6,0.8$ & 0.9 & 1.29 & 780 & $0.8 e-3$ & $1.79 e-5$ & 0.026
\end{tabular}
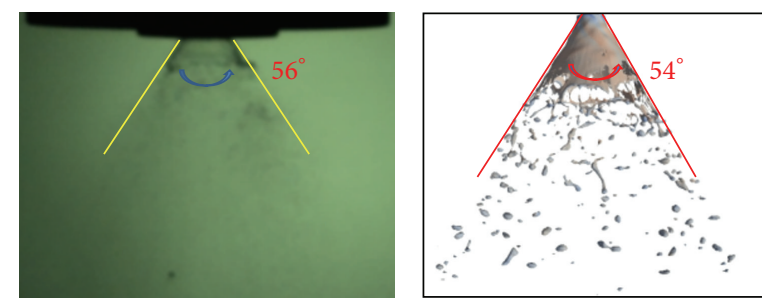

(a) $\triangle P=0.4 \mathrm{MPa}$
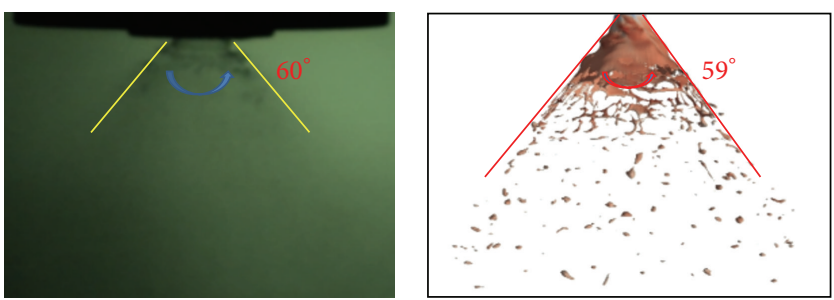

(b) $\Delta P=0.8 \mathrm{MPa}$

FIGURE 4: Comparison of experimental and simulation photography of the spray at $0.4 \mathrm{MPa}$ and $0.8 \mathrm{MPa}$ injection pressure $(\triangle P), 0.1 \mathrm{MPa}$ ambient pressure, and $t=3 \mathrm{~ms}$.

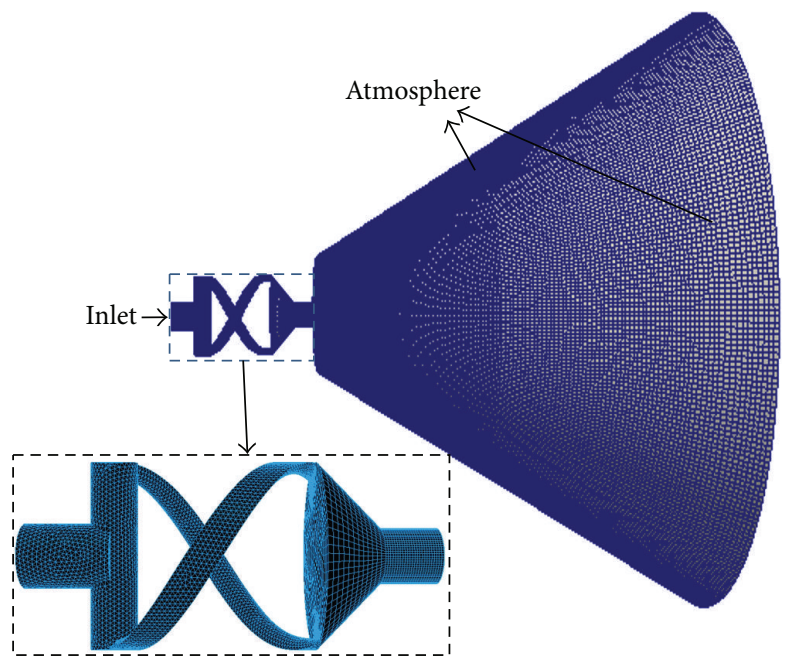

FIGURE 5: Geometry of the injector, calculation domain, and boundary condition.

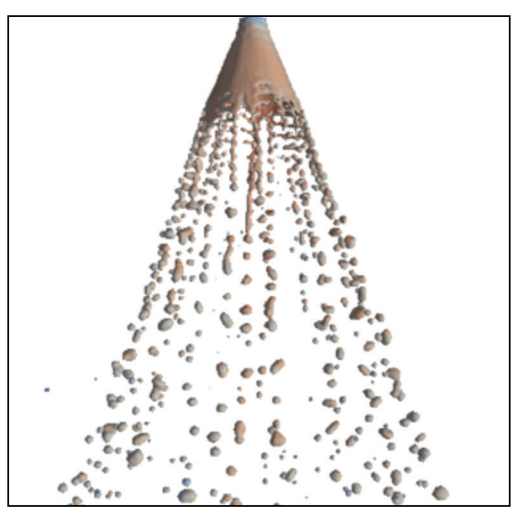

$\Delta P=0.4 \mathrm{MPa}$

(a)

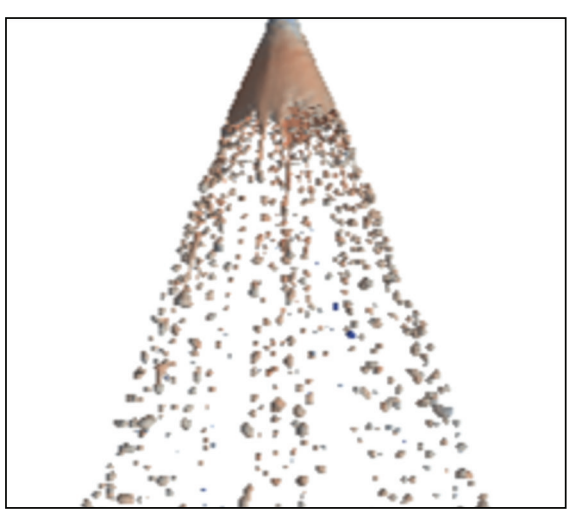

$\Delta P=0.6 \mathrm{MPa}$

(b)

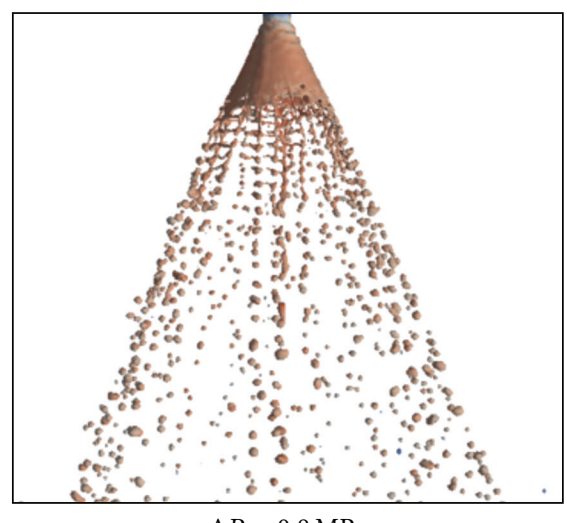

(c)

FIGURE 6: Spray structures of fully developed spray at different injection pressures. 


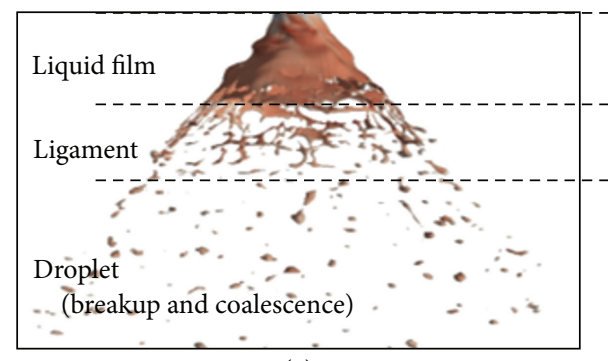

(a)

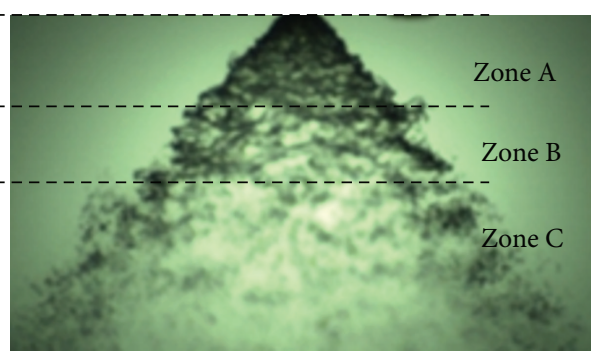

(b)

FIGURE 7: Spray profile of a hollow cone swirling spray. (a) Simulation, (b) experiment.

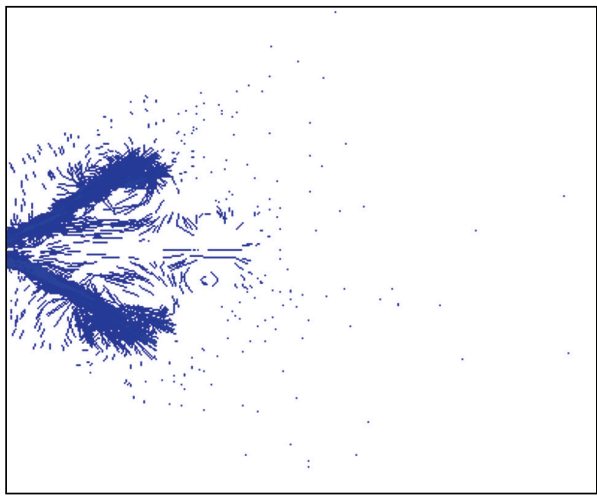

(a)

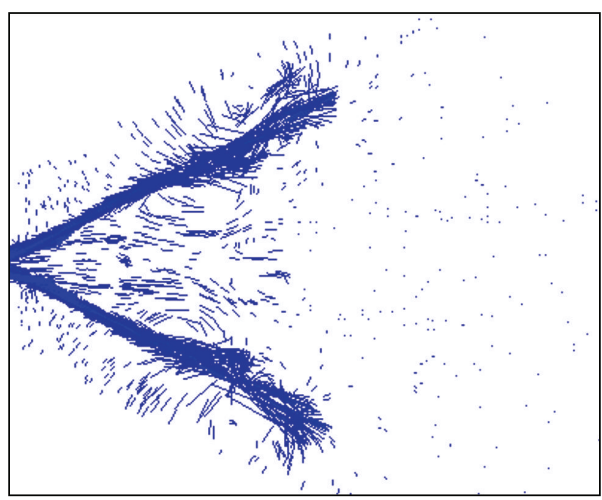

(c)

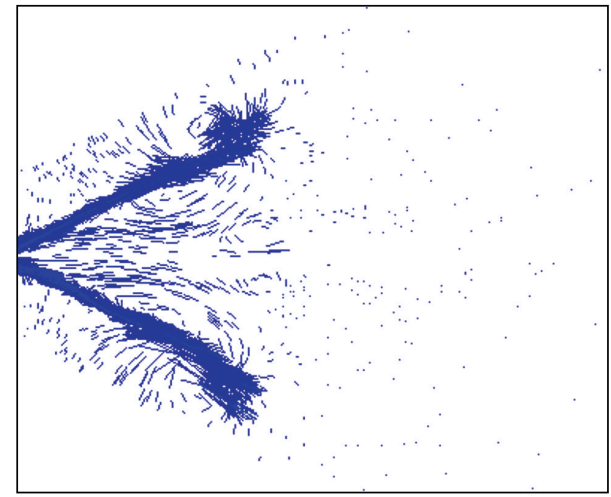

(b)

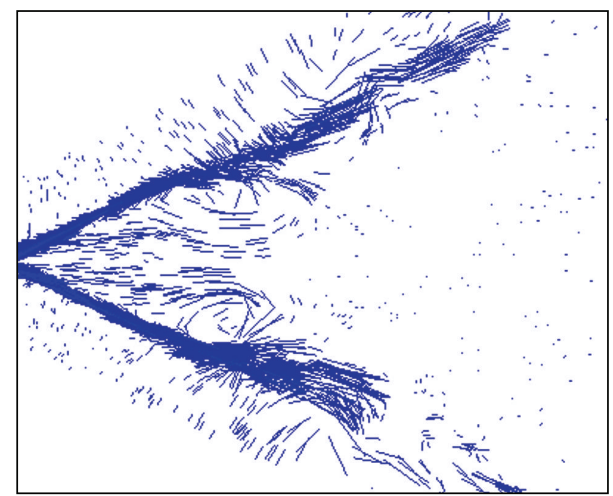

(d)

Figure 8: Velocity field of a central plane ( $\Delta P=0.6 \mathrm{MPa}$, (a) $t=1.0 \mathrm{~ms}$, (b) $t=1.5 \mathrm{~ms}$, (c) $t=2.0 \mathrm{~ms}$, and (d) $t=3.0 \mathrm{~ms})$.

"liquid film zone," where surface instability occurs and grows. Zone B is the "ligament zone," where liquid film breaks up and ligaments are generated. Zone C is the "droplet zone," where ligaments break up into droplets. Droplet deformation, secondary breakup, and coalescence occur in this region.

Figure 8 shows the velocity vector field of a central plane for the spray. Due to the complex droplet motion and interaction between gas and liquid, strong vortices are generated near the gas-liquid interface. Inside the hollow cone section, a vortical flow field is generated at downstream locations and the recirculation zone is generated due to the entrainment of air by the liquid sheet. Strong turbulent structure is created inside the recirculation zone, thus promoting the breakup of ligaments and droplets secondary atomization.

Figure 9 shows the axial velocity profile of different times at center line for the spray at $\Delta P=0.6 \mathrm{MPa}$, which indicates the characteristics of the recirculation zone. As shown in Figure 10, two recirculation zones exist in the hollow cone spray; they are called the geometric recirculation zone and the central recirculation zone. The geometric recirculation zone exists near the exit of the injector nozzle, which is emerged due to the bluff body effect of cylindrical liquid sheet. For this case, the length of the geometric recirculation zone is about 2D. Downstream of the spray cone, the central recirculation 


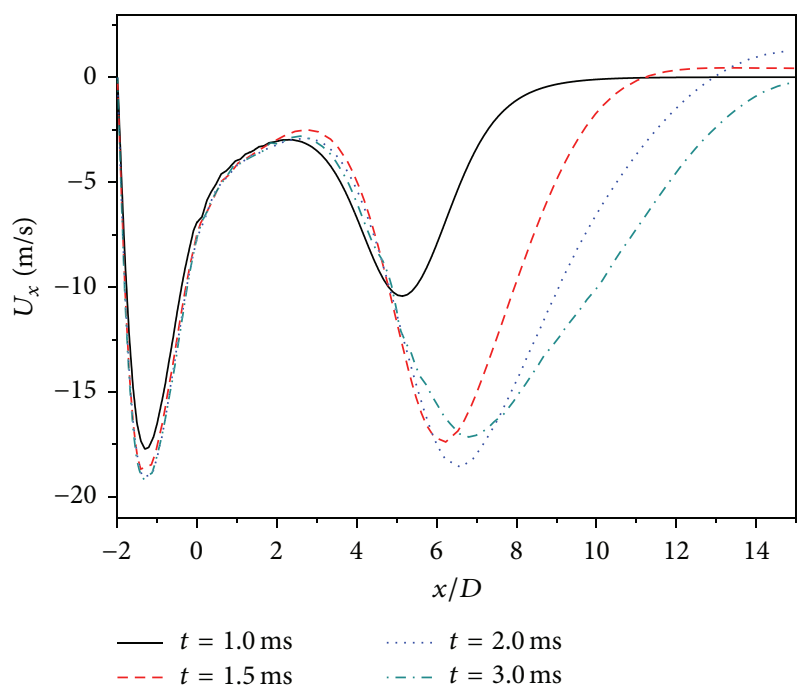

Figure 9: Axial velocity profile at center line $(\triangle P=0.6 \mathrm{MPa})$.

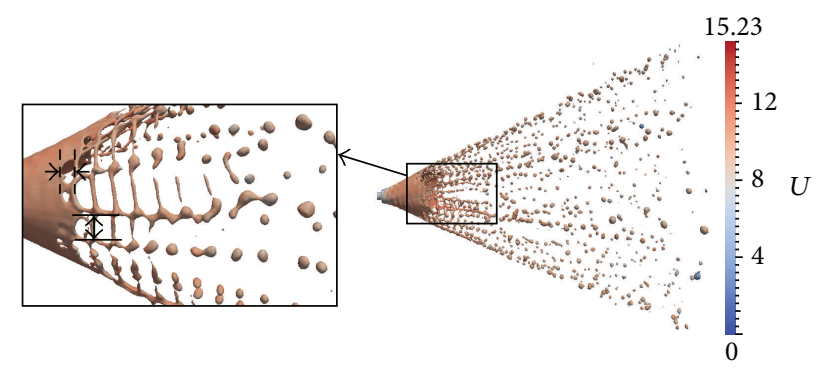

Figure 10: Ligament formation from liquid sheet $(\triangle P=0.6 \mathrm{MPa}$, $t=3 \mathrm{~ms})$.

zone is generated near the location of $x / D=4$, located at the "ligament zone." As time passes, the central recirculation zone grows larger and moves downstream. The length of the central recirculation zone is about $6 \mathrm{D}$, which is larger than the length of the geometric recirculation zone.

3.3. Ligament Formation. The breakup process of swirling liquid sheet could be described as follows: at the exit of injector nozzle, initial perturbation is generated due to disturbance factors such as inner-nozzle turbulence, boundary layer effect, and aerodynamic force. As shown in Figure 10, surface waves can be observed in the axial direction and the transverse direction as pointed out by dashed lines and solid lines, respectively. As the wave grows, ligaments are created. Two types of ligaments exist in the spray. One is the striptype ligament created by the transverse instability. This type of ligaments spread along the axial direction and capillary waves are created on the ligament due to surface tension. Another type is the ring-like ligament created by the axial instability. These two types of ligament interweave and net-like structure of ligament zone can be observed.

The features of surface waves directly affect the primary breakup of liquid film and the droplets distribution status. Figure 11 shows the spray structure observed from the front

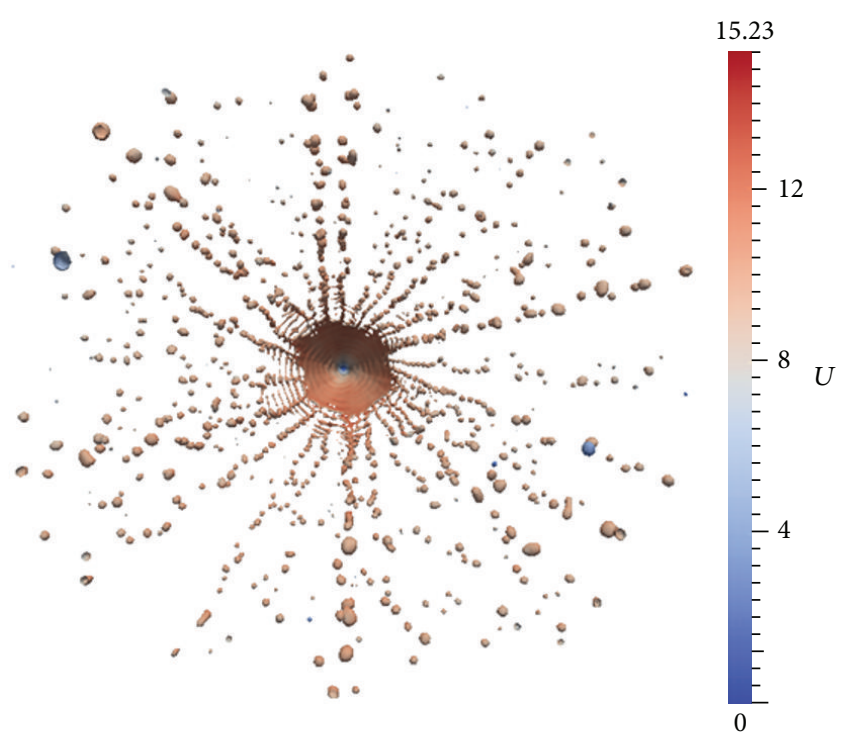

FIGURE 11: The front elevation of spray structure $(\Delta P=0.6 \mathrm{MPa}$, $t=3 \mathrm{~ms})$.

elevation, from which the droplets distribution status can be observed. Due to the net-like structure of ligament, droplets are dispersed around the circumferential direction.

3.4. Droplet Formation from Ligament. In Section 3.3, we have indicated that, for a swirling jet, liquid sheet breaks up into several ligaments firstly, and then droplets pinch off from ligaments. The ligaments generated from the liquid sheet are similar as several liquid jets with no "injection nozzle" and the breakup mechanism of ligaments is approximate to the breakup of a liquid jet. As the velocity of liquid jet increases, four regimes of breakup mechanism can be distinguished on a plot of Re versus Oh. They are Rayleigh capillary region, first wind-induced region, second wind-induced region, and atomization region [32]. The local Reynold's number and local Ohnesorge number are defined by

$$
\begin{aligned}
& \mathrm{Oh}=\frac{\mu_{l}}{\left(\rho_{l} a \sigma\right)^{1 / 2}}, \\
& \operatorname{Re}=\frac{\rho_{l} a u}{\mu_{l}} .
\end{aligned}
$$

The plot of ligament local Re and Oh for the cases of the present study is shown in Figure 12. In the present study, the Re number of ligaments is scattered in a range of 600 800 and the $\mathrm{Oh}$ number of ligaments is scattered in a range of $0.01 \sim$ 0.02. As shown in Figure 13, the four regions are separated by lines. The points in the present study are located at the Rayleigh capillary region.

Strutt and Rayleigh [33] introduced the mechanism of breakup of a low speed cylindrical liquid jet (ligament). For unstable cylindrical ligaments, axisymmetric oscillation occurs and grows due to the surface tension force, and ligaments break up into dispersed droplets eventually. According 


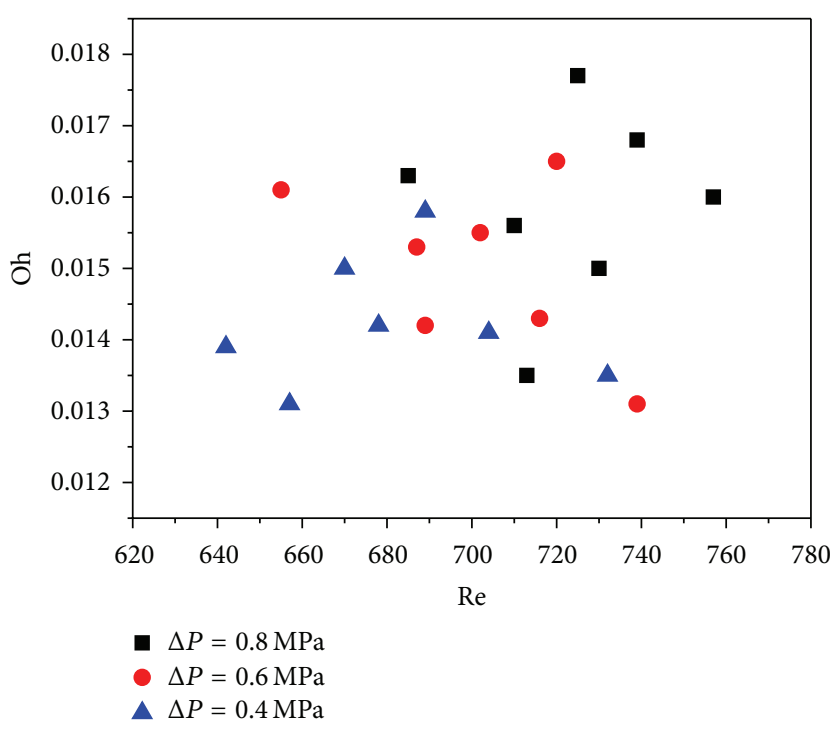

FiguRE 12: Ligament local Re and Oh for cases in the present study.

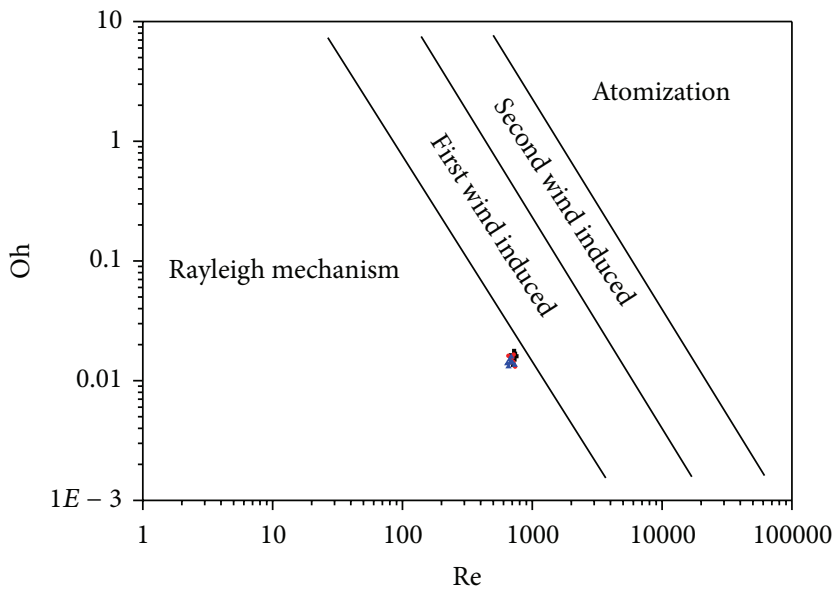

FIGURE 13: Four regimes of breakup mechanism in dependence on local Re number and Oh number.

to the Rayleigh theory, the ideal diameter of resultant droplet is estimated as

$$
D=1.89 d \text {. }
$$

Figure 14(a) shows the ideal model of Rayleigh breakup; the ligament is expected to break up into droplets of same diameter with even space. Figure 14(b) shows the ligament breakup example of numerical simulation. The wavelength of capillary wave is about 4.0 4.3 times the diameter of the ligament. The capillary waves pinch off from the neck of the ligament and spherical droplets are formed due to the surface tension force. The diameter of droplet is about 1.7 2.0 times the ligament diameter, which shows a similar tendency to the ideal model. But the actual flow field is complex, the droplet generation process is more random, and the droplet diameter distribution range is wider than the ideal model.

Figure 15 shows the temporal droplet formation process $(\Delta P=0.6 \mathrm{MPa})$. The breakup of ligament is much more complex than the ideal model of Rayleigh theory. At the primary breakup zone, ligaments break up into numerous irregularly shaped droplets. After the primary breakup, secondary breakup and coalescence occur downstream of the spray. As pointed out by the blue arrow in Figure 15, small droplets generated by primary breakup collide due to their velocity difference. Larger droplet is formed after the collision and its shape becomes spheroid under the effects of surface tension. Another important behavior of primary breakup droplets is secondary breakup. As shown in Figure 15, pointed out by the red arrow, the large ligament generated by primary breakup becomes deformed due to the aerodynamic force, the neck becomes thinner and is pinched off by surface tension, and smaller droplets are generated.

The secondary breakup and coalescence directly affect the distribution characteristic of droplets. Figure 16 shows the droplet size distribution at different axial location $(\triangle P=$ $0.6 \mathrm{MPa}$ ). At the primary breakup zone (Figure 16(a)), most 


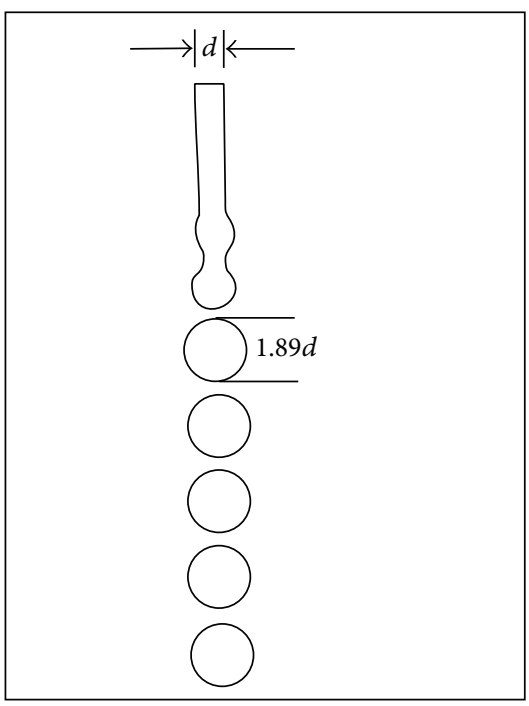

(a)

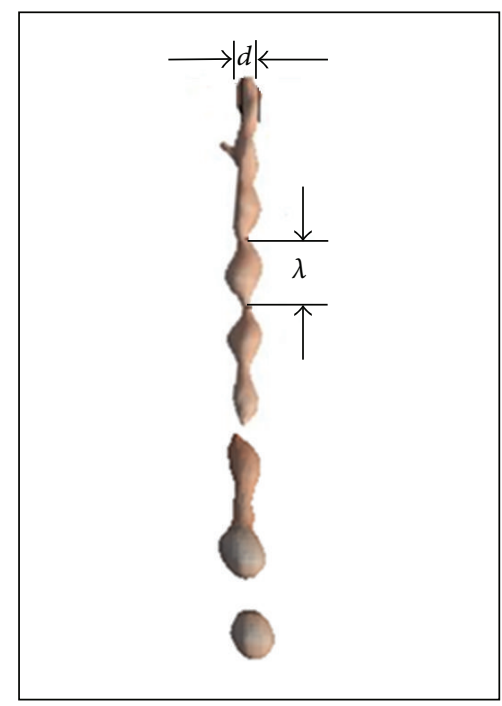

(b)

FIgURE 14: Rayleigh mode of ligament breakup: (a) ideal model, (b) ligament breakup example of numerical simulation.

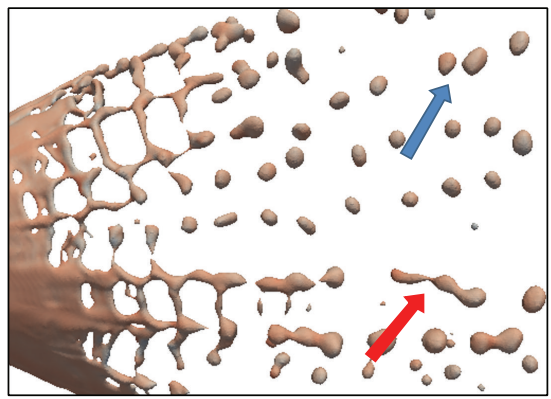

(a) $t=2.10 \mathrm{~ms}$

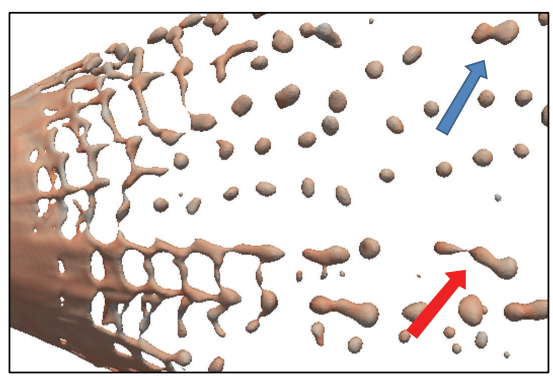

(d) $t=2.13 \mathrm{~ms}$

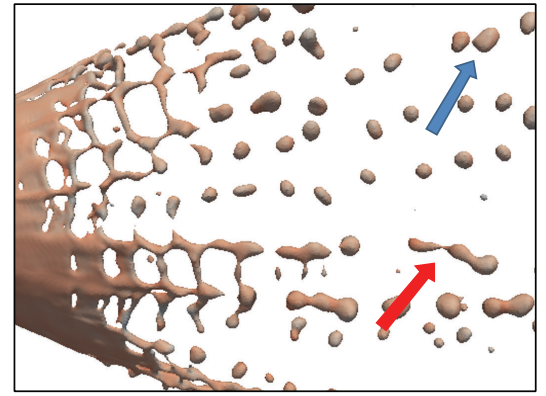

(b) $t=2.11 \mathrm{~ms}$

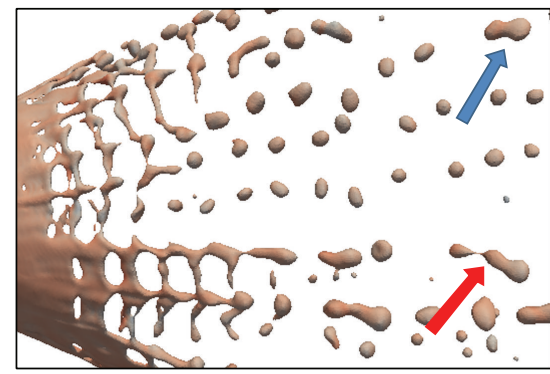

(e) $t=2.14 \mathrm{~ms}$

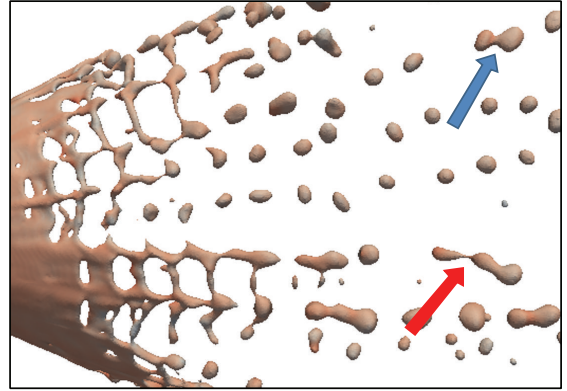

(c) $t=2.12 \mathrm{~ms}$

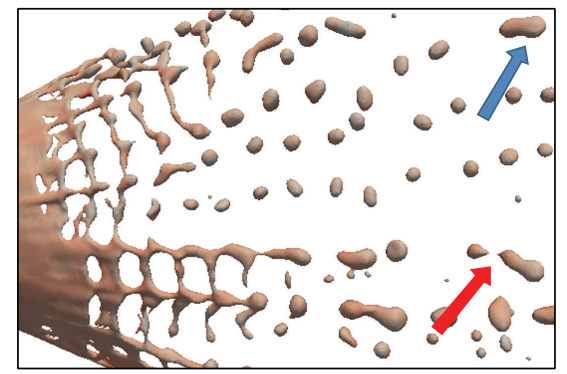

(f) $t=2.15 \mathrm{~ms}$

FIgURE 15: The temporal droplet formation process $(\triangle P=0.6 \mathrm{MPa})$.

of the droplets are generated by the Rayleigh breakup of ligaments and the size of droplets is about $100 \sim 175 \mu \mathrm{m}$, and the size distribution of droplets is intensive at this region. At the downstream location, secondary breakup and coalescence create larger and smaller droplets, resulting in a wider distribution curve as the axial direction increase.

\section{Conclusions}

In the present study, a LES-VOF model is used for computing the atomization process of swirling sprays in gas turbine engines. With fine grid resolution, the ligament and droplet formation processes are captured in detail. The mechanisms of ligament and droplet formation are investigated by analyzing the simulation results at various injection pressures. The findings are summarized as follows.

The hollow cone swirling spray can be divided into three zones. They are the "liquid film zone," the "ligament zone," and the "droplet zone." Inside the hollow cone section of the "ligament zone," a central recirculation zone is generated due to the entrainment of air by the liquid sheet and strong turbulent structures promote the breakup of ligaments. 


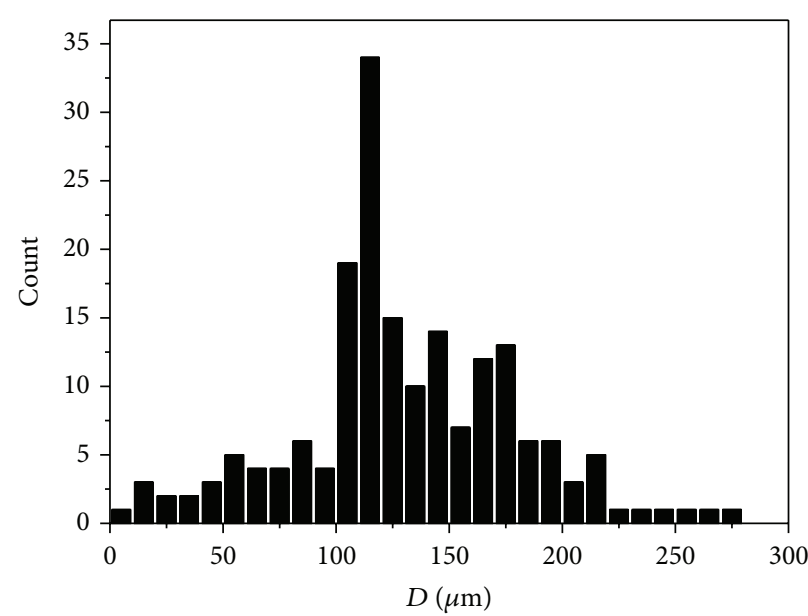

(a)

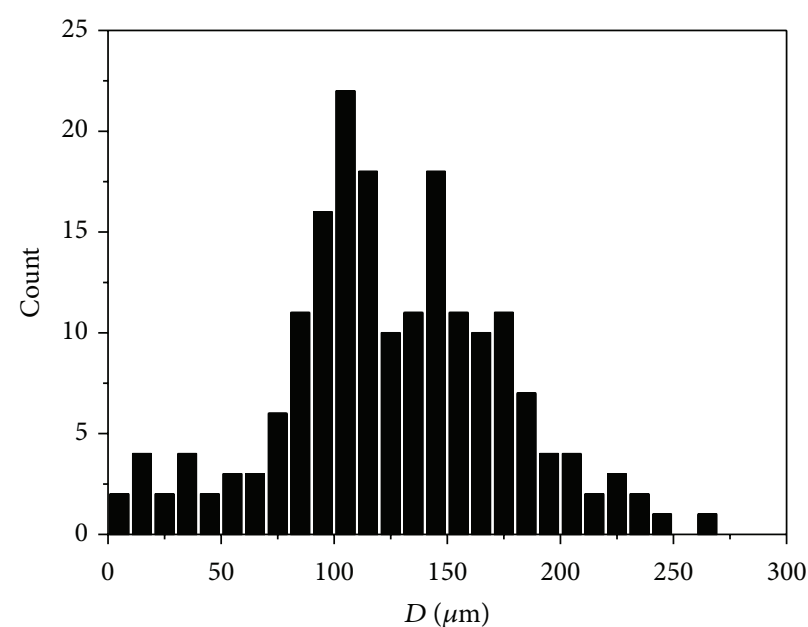

(b)

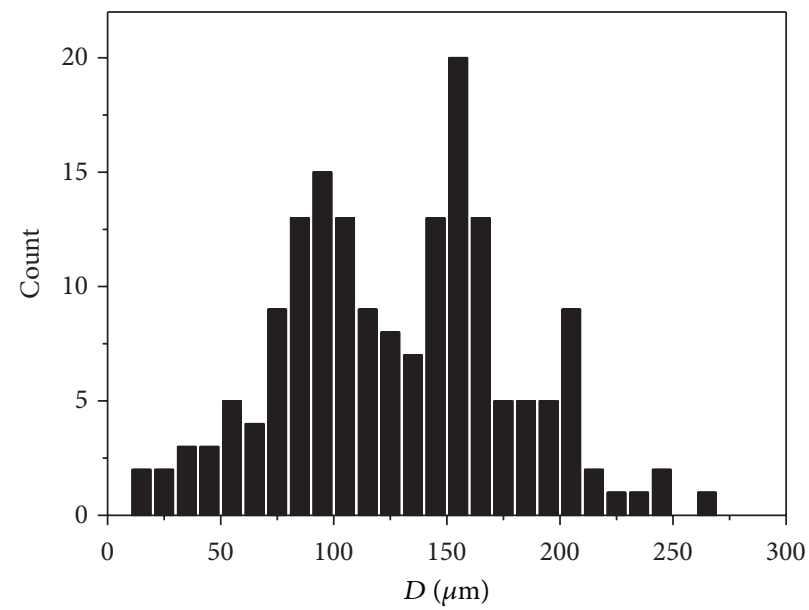

(c)

FIGURE 16: Droplet size distribution at different axial location ( $\triangle P=0.6 \mathrm{MPa}$ ): (a) $7 \mathrm{~mm}$ axial location, (b) $9 \mathrm{~mm}$ axial location, and (c) $11 \mathrm{~mm}$ axial location.

At the exit of injector nozzle, surface instability occurs due to disturbance factors such as inner-nozzle turbulence, boundary layer effect, and aerodynamic force. The features of surface waves directly affect the primary breakup of liquid film. Axial and transverse mode instabilities produce a netlike structure ligament zone.

According to the local $\mathrm{Re}$ and $\mathrm{Oh}$ of ligaments in the present study, the breakup mechanism of ligaments is located at the Raleigh capillary region. Axisymmetric oscillation occurs due to the surface tension force and the capillary waves pinch off from the neck of the ligament. The diameters of droplets formed by the primary breakup are about 1.7 2.0 times the ligament diameter. Secondary breakup and coalescence occur at the "droplet zone," resulting in a wider distribution curve as the axial direction increase.

The results presented here can contribute towards a full understanding of the breakup of swirling jet and can be helpful in the design of injector system in gas turbine engines.

\section{Competing Interests}

The authors declare that they have no competing interests.

\section{References}

[1] A. Lefebvre, Atomization and Sprays, CRC Press, New York, NY, USA, 1988.

[2] K. Ramamurthi and T. J. Tharakan, "Flow transition in swirled liquid sheets," AIAA Journal, vol. 36, no. 3, pp. 420-427, 1998.

[3] M. Sommerfeld and H.-H. Qiu, "Detailed measurements in a swirling particulate two-phase flow by a phase-Doppler anemometer," International Journal of Heat and Fluid Flow, vol. 12, no. 1, pp. 20-28, 1991.

[4] M. Vanierschot and E. Van den Bulck, "Hysteresis in flow patterns in annular swirling jets," Experimental Thermal and Fluid Science, vol. 31, no. 6, pp. 513-524, 2007.

[5] E. A. Ibrahim and T. R. McKinney, "Injection characteristics of non-swirling and swirling annular liquid sheets," Proceedings 
of the Institution of Mechanical Engineers, Part C: Journal of Mechanical Engineering Science, vol. 220, no. 2, pp. 203-214, 2006.

[6] J. Ponstein, "Instability of rotating cylindrical jets," Applied Scientific Research, vol. 8, no. 1, pp. 425-456, 1959.

[7] Y. Liao, A. T. Sakman, S. M. Jeng, M. A. Jog, and M. A. Benjamin, "A comprehensive model to predict simplex atomizer performance," Journal of Engineering for Gas Turbines and Power, vol. 121, no. 2, pp. 285-294, 1999.

[8] A. A. Ibrahim and M. A. Jog, "Nonlinear instability of an annular liquid sheet exposed to gas flow," International Journal of Multiphase Flow, vol. 34, no. 7, pp. 647-664, 2008.

[9] K.-C. Chang, M.-R. Wang, W.-J. Wu, and C.-H. Hong, "Experimental and theoretical study on hollow-cone spray," Journal of Propulsion and Power, vol. 9, no. 1, pp. 28-34, 1993.

[10] Y. Khavkin, "About swirl atomizer mean droplet size," Atomization and Sprays, vol. 11, no. 6, pp. 757-774, 2001.

[11] A. Tratnig and G. Brenn, "Drop size spectra in sprays from pressure-swirl atomizers," International Journal of Multiphase Flow, vol. 36, no. 5, pp. 349-363, 2010.

[12] L.-J. Yang, Q.-F. Fu, Y.-Y. Qu, W. Zhang, M.-L. Du, and B.-R. Xu, "Spray characteristics of gelled propellants in swirl injectors," Fuel, vol. 97, pp. 253-261, 2012.

[13] J. Liu, X. Q. Zhang, Q. L. Li, and Z. G. Wang, "Effect of geometric parameters on the spray cone angle in the pressure swirl injector," Proceedings of the Institution of Mechanical Engineers, Part G: Journal of Aerospace Engineering, vol. 227, no. 2, pp. 342-353, 2013.

[14] X. Zheng, J. Lowengrub, A. Anderson, and V. Cristini, "Adaptive unstructured volume remeshing-II: application to two- and three-dimensional level-set simulations of multiphase flow," Journal of Computational Physics, vol. 208, no. 2, pp. 626-650, 2005.

[15] T. Ménard, S. Tanguy, and A. Berlemont, "Coupling level set/ VOF/ghost fluid methods: validation and application to 3D simulation of the primary break-up of a liquid jet," International Journal of Multiphase Flow, vol. 33, no. 5, pp. 510-524, 2007.

[16] O. Desjardins, V. Moureau, and H. Pitsch, "An accurate conservative level set/ghost fluid method for simulating turbulent atomization," Journal of Computational Physics, vol. 227, no. 18, pp. 8395-8416, 2008.

[17] E. De Villiers, A. D. Gosman, and H. G. Weller, "Large eddy simulation of primary diesel spray atomization," SAE Technical Paper 2004-01-0100, SAE International, 2004.

[18] M. Herrmann, "A balanced force refined level set grid method for two-phase flows on unstructured flow solver grids," Journal of Computational Physics, vol. 227, no. 4, pp. 2674-2706, 2008.

[19] M. Herrmann, "Detailed numerical simulations of the primary atomization of a turbulent liquid jet in crossflow," Journal of Engineering for Gas Turbines and Power, vol. 132, no. 6, Article ID 061506, 2010.

[20] M. Herrmann, M. Arienti, and M. Soteriou, "The impact of density ratio on the primary atomization of a turbulent liquid jet in crossflow," in Proceedings of the ASME Turbo Expo 2010: Power for Land, Sea, and Air, pp. 823-832, American Society of Mechanical Engineers, October 2010.

[21] J. Shinjo and A. Umemura, "Simulation of liquid jet primary breakup: dynamics of ligament and droplet formation," International Journal of Multiphase Flow, vol. 36, no. 7, pp. 513-532, 2010.
[22] J. Shinjo and A. Umemura, "Surface instability and primary atomization characteristics of straight liquid jet sprays," International Journal of Multiphase Flow, vol. 37, no. 10, pp. 1294-1304, 2011.

[23] G. A. Siamas, X. Jiang, and L. C. Wrobel, "Numerical investigation of a perturbed swirling annular two-phase jet," International Journal of Heat and Fluid Flow, vol. 30, no. 3, pp. 481-493, 2009.

[24] J. U. Brackbill, D. B. Kothe, and C. Zemach, "A continuum method for modeling surface tension," Journal of Computational Physics, vol. 100, no. 2, pp. 335-354, 1992.

[25] J. C. Harris and S. T. Grilli, "A perturbation approach to large eddy simulation of wave-induced bottom boundary layer flows," International Journal for Numerical Methods in Fluids, vol. 68, no. 12, pp. 1574-1604, 2012.

[26] W. F. Noh and P. Woodward, "SLIC (Simple Line Interface Calculation)," in Proceedings of the Fifth International Conference on Numerical Methods in Fluid Dynamics June 28-July 2, 1976 Twente University, Enschede, vol. 59 of Lecture Notes in Physics, pp. 330-340, Springer, Berlin, Germany, 1976.

[27] D. L. Youngs, "An interface tracking method for a 3D Eulerian hydrodynamics code," Tech. Rep. AWRE/44/92/35, Atomic Weapons Research Establishment, 1987.

[28] Y. Renardy and M. Renardy, "PROST: a parabolic reconstruction of surface tension for the volume-of-fluid method," Journal of Computational Physics, vol. 183, no. 2, pp. 400-421, 2002.

[29] O. Ubbink, Numerical Prediction of Two Fluid Systems with Sharp Interfaces, University of London, 1997.

[30] S. Muzaferija and M. Peric, "Computation of free-surface flows using interface-tracking and interface-capturing methods," in Nonlinear Water Wave Interaction, O. Mahrenholtz and M. Markiewicz, Eds., pp. 59-100, Computational Mechanics Publications, Southampton, UK, 1998.

[31] OpenCFD Ltd, OpenFoam-1.6 Documentation, The Open Source CFD Toolbox, OpenCFD Ltd, 2009.

[32] W. A. Sirignano and C. Mehring, "Review of theory of distortion and disintegration of liquid streams," Progress in Energy and Combustion Science, vol. 26, no. 4, pp. 609-655, 2000.

[33] J. W. Strutt and L. Rayleigh, "On the instability of jets," Proceedings London Mathematical Society, vol. 10, no. 1, pp. 4-13, 1878. 


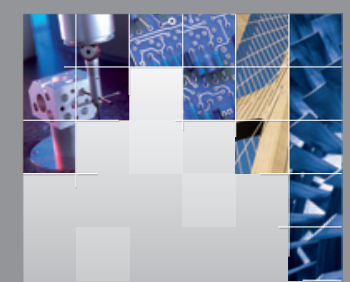

\section{Enfincering}
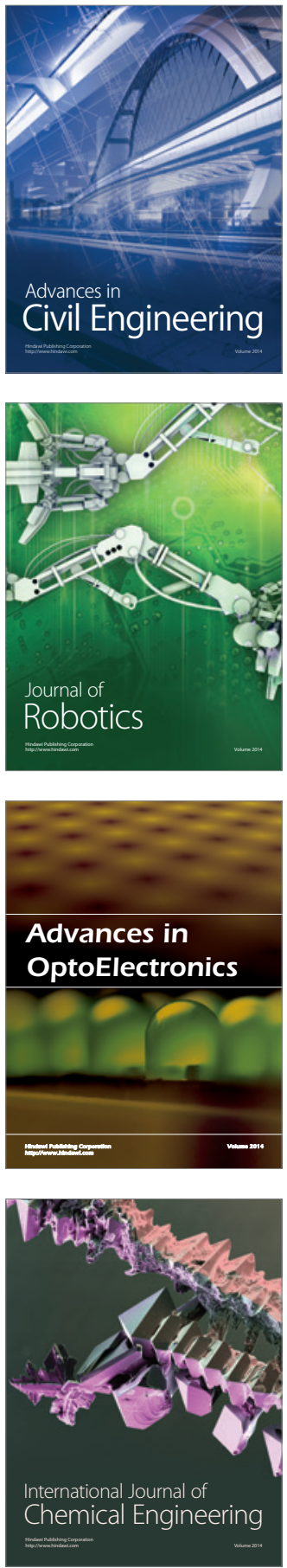

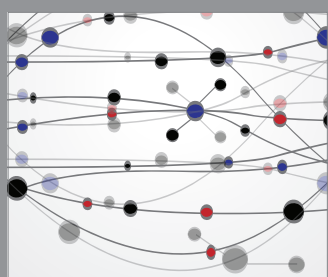

The Scientific World Journal

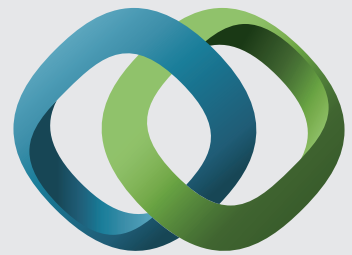

\section{Hindawi}

Submit your manuscripts at

http://www.hindawi.com
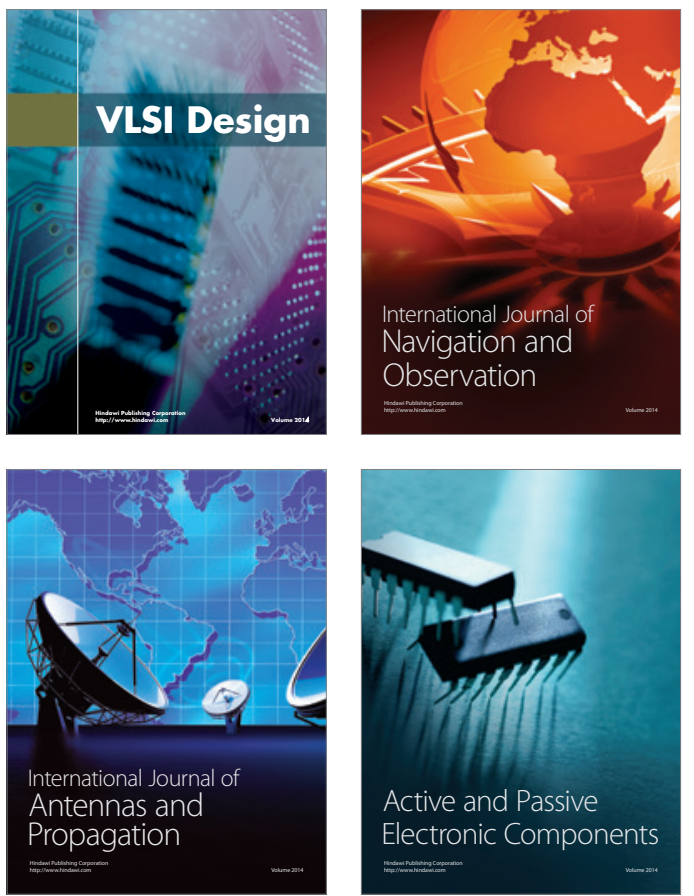
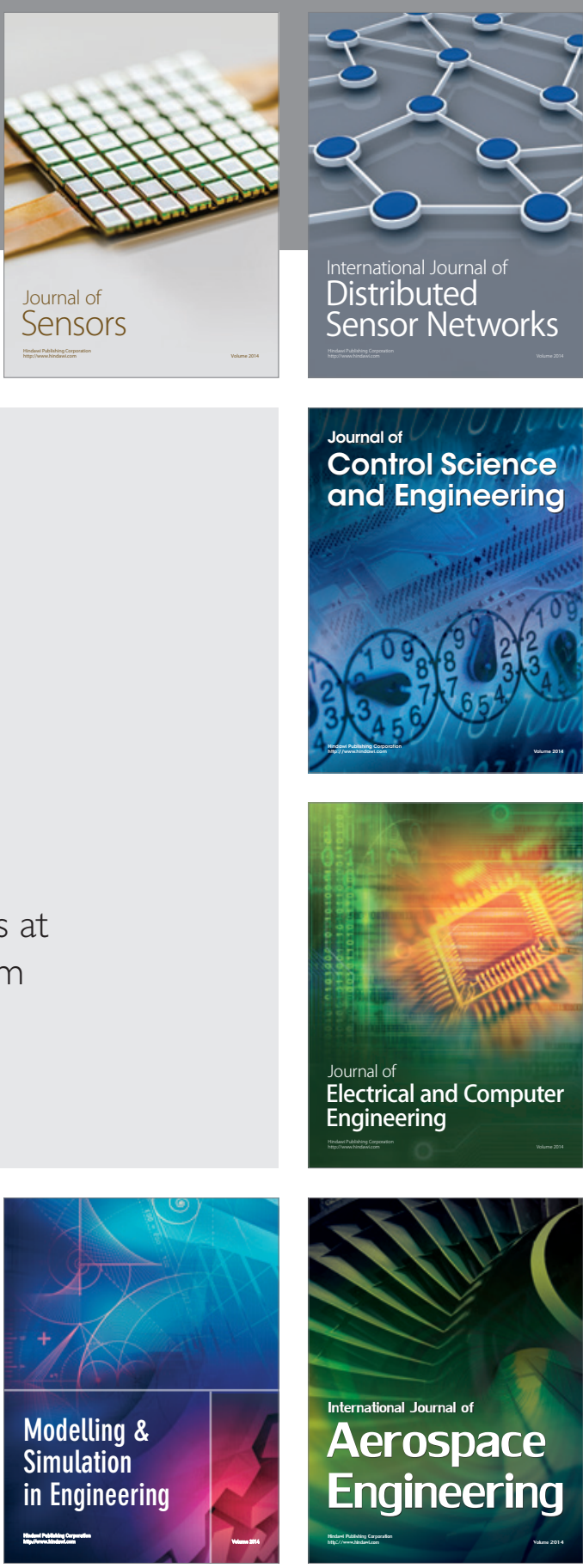

International Journal of

Distributed

Sensor Networks

Journal of

Control Science

and Engineering
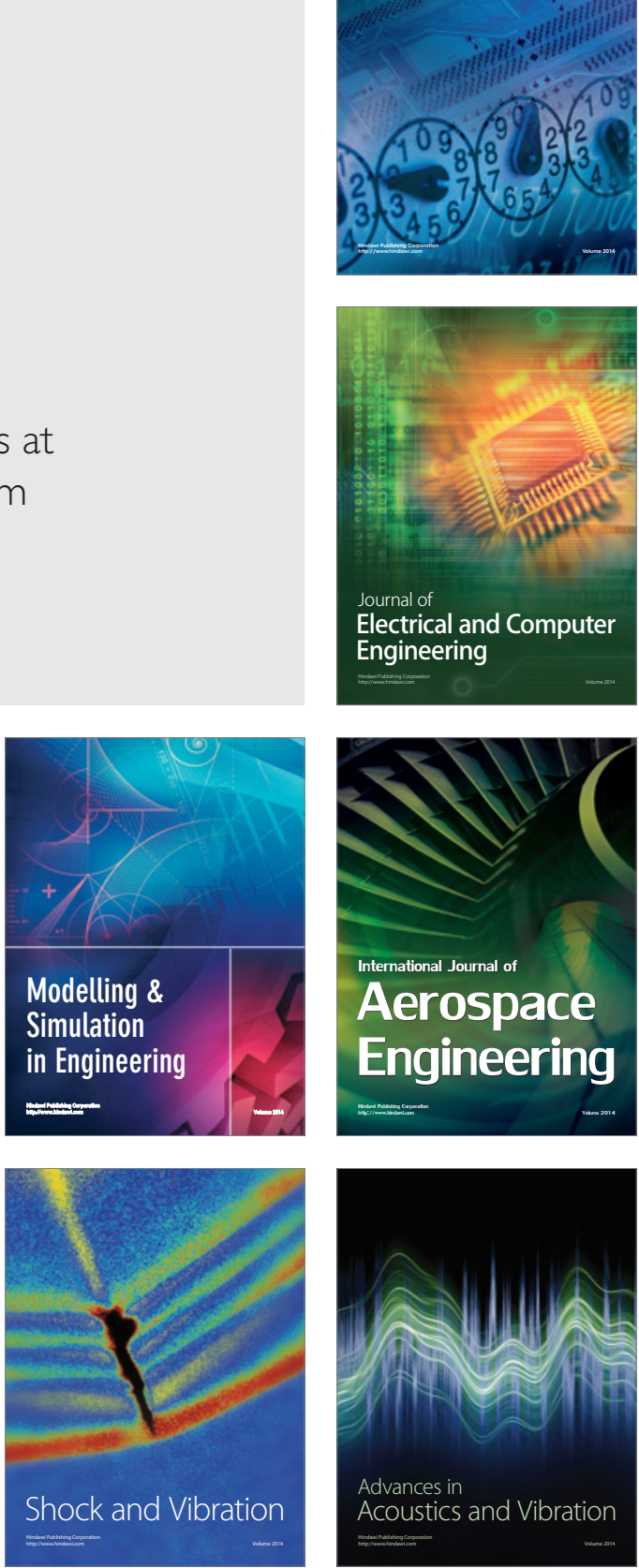